\title{
Students' Identities and its Relationships with their Engagement in an Online Learning Community
}

\author{
https://doi.org/10.3991/ijet.v14i05.8196 \\ Fariza Khalid \\ Universiti Kebangsaan Malaysia, Bangi Selangor, Malaysia \\ fariza.khalid@ukm.edu.my
}

\begin{abstract}
Communities of practice's approaches have been proven to be effective in enhancing students' learning as well as helping them to cultivate inter-personal skills, especially within the higher education system. An important development in relation to participation in communities of practice is members' identities. This study was conducted with the aim of understanding students' identities in relation to their participation in an online community and how the dimensions of their identities correlated to each other. The research participants were 123 first-year students who were involved in collaborative sharing activities via an online community, using Weebly. Data was collected using a set of questionnaires that discussed four main dimensions of identities: personal, professional, as learners, and as members of communities. Data was analysed using SPSS version 22. The overall findings offer a detailed description of students' identities. A high positive correlation was found between students' prior knowledge and their motivation, commitment and beliefs with regard to the benefits of online communities. The only dimension of students' identities that lacked correlation with other dimensions was students' openness. The findings highlight the importance of understanding different aspects of identities and how this helps to enhance engagement in online communities. The findings are significant in terms of establishing a deeper understanding on learning process within a social learning theory.
\end{abstract}

Keywords-Online, communities of practice, social learning, motivation, tertiary education, identities.

\section{Introduction}

In line with the existence of Internet connections and various Learning Management Systems (LMS) available today, online collaborative sharing activities are considered an important activity to expand students' knowledge and understanding. Through online discussions, assessment of students' learning is also possible [1], [2]. An online learning community can be built through interaction among the members, i.e. through sharing thoughts, asking questions and providing feedback [3]. Sharing activities via online communities also allow greater flexibility than traditional, faceto-face mentoring; they save users' time as the users do not have to travel, but can instead work from their classrooms or at home and at their own pace [4], [5]. [6] sug- 
gest that discussions in online communities allow for in-depth meaning-making and help construct students' understanding. This is caused by the fact that in face-to-face discussions, students do not have enough time to think before they give their responses, but in contrast, in online discussions, students have ample time to read, think about and reply to the discussions. Moreover, discussions with online community members also allow the development of open and supportive relationships and friendships, and greater cohesiveness within the learning group [7]. Furthermore, if the relationships in online communities are developed informally, this leads to greater engagement than through the establishment of more formal relationships [8].

\subsection{Factors influencing the level of participation in online communities}

One of the factors leading to participation in online sharing activities is trust, and it is stressed by [9] and [10] that without the element of trust, members of communities are not able to freely share their ideas and learn from each other. Trust is built when community members can overcome their limitations and lack of knowledge, which gives them the feeling that they are not alone with their problems. Trust is also developed when teachers are able to remove their fears of stepping over the professional boundaries of others [11].

In a community where members have different backgrounds and experiences, it can be problematic for certain members to accept others into their 'circle of friends' because individuals may have their own perceptions about their peers which then affect their engagement. Therefore, it is paramount that in the early stages, members of any community build bonds and relationships between themselves so as to develop a 'friendly climate' [12], [13], [14] and so that the values of trust and openness can be developed. In a friendly climate, people use positive words, accept group members and acknowledge others for their contributions. [12] found that the members of the online community in their study (nursing students) felt a sense of belonging to their community when they were acknowledged and felt validated by others. They posit that these are key characteristics of good relationships in online communities. Adding to this, [14] emphasizes the importance of 'becoming friends', as this will enhance cooperative activities among community members and, as an outcome, individuals in communities will be more likely to participate in and contribute to the group, knowing that their ideas are respected and accepted.

There may also be hindering factors that obstruct members from fully participating in online communities. Researchers such as [11] identify that some of the members of the online communities in their study kept quiet when facing outsiders. Their analysis indicates that these participants felt constrained by their face-to-face teaching community. They were reluctant to participate in sharing activities through the online communities because of their rigid and tight face-to-face social networks. Participants in [11] study tended to share with existing community members and showed reluctance to share with new members so as to retain their superior status. [1] describes this phenomenon as localism, by which members let their membership of departmental communities define their boundaries, leading them to fail to transcend these boundaries to develop new communities with diverse groups of people. This is explained by 
[10] as an issue of boundaries between members. When community members develop tight and close relationships with their peers, it is difficult to open the community up to new members, as letting new members in might influence the community's current shared repertoire and practice.

Another important factor is having sufficient time, especially during school hours, to get online. School leaders have a direct influence on their school's culture. Therefore, [15], [16] state that it is crucial that school leaders facilitate a culture in which teachers can become part of learning communities. When learning communities are developed within the school culture, teachers will be motivated to strive towards continuous learning [17].

[18] Asserts that culture is the key condition that may influence teachers' ability to exercise their agency and control change. Moreover, recent research has indicated that knowledge sharing, communication and learning in communities are all affected by the cultural values of individual participants [19], [20]. [10] write: People's willingness to ask questions that reveal their 'ignorance', disagree with others in public, contradict known experts, discuss their problems, follow others in the thread of conversation - all these behaviours vary greatly across cultures (p. 118).

Another contributing element to successful online collaborative sharing activities is members' individual beliefs and attitudes [14], [21], [22] regarding the activities themselves. When members perceive their online collaboration activities as useful and the platform as easy to use, they will become active participants. From the perspective of Reasoned Action Theory [23], an attitude towards an object or task may arise from beliefs about the object or task. Therefore, members' beliefs and attitudes towards online tasks may influence their readiness to interact and share online. In turn, this may affect their motivational level. Self-efficacy theory, which states that 'people's judgement of their capabilities to organize and execute courses of action required to attain designated types of performances' [24] stresses that the way participants perceive their ability to carry out the expected behaviour is the most important precondition for any behavioural change, and may affect individuals' responsibility, role and willingness to participate in reciprocal sharing activities. This means that when members of any community have a low level of self-efficacy, it is difficult for the community to survive. However, [25] believe that, despite this, given emotional support, members with low self-efficacy will gain more confidence and the desire to participate.

Overall, the factors leading to participation in online learning communities can be summarised in two main categories: external factors and internal factors. External factors cover aspects like time, support and culture, while internal factors include trust, openness, beliefs, self-efficacy and attitudes. Internal factors are closely related to identities; [26] stress that how members participate in, perform and commit to any activities is determined by their identities, and that an understanding of members' identities is central to any analysis of their effectiveness, work and lives. [26] also states that identity plays an important role in providing a rationale for understanding why and how members are committed to their communities. The significance of the issue of identity in learning communities is highlighted by [27]: Issues of identity are 
an integral aspect of a social theory of learning and are thus inseparable from issues of practice, community and meaning. (p. 145)

\subsection{Factors influencing the level of participation in online communities}

A simple definition of identity is posited by [28] as 'what makes you similar to yourself and different from others' (p. 3). Meanwhile, [29] offer the concept of identity as 'who or what someone is, the various meanings someone can attach to oneself or the meaning attributed to oneself by others' (p. 282). [30] conducted her research using a qualitative approach which involved data generation from in-depth interviews with her respondents. This study utilised the dimensions of identities as a framework, and changed the sub-categories that arose from the qualitative analysis into a set of questionnaires. The aims of this study were to identify students' identities in relation to their participation in online communities using the four dimensions of identities [30] and to measure the relationships between the different dimensions of identities.

[30] Focuses on understanding the dimensions of identities in relation to their participation in online communities. The analysis of her qualitative data, using a grounded approach for data analysis, showed four emerging dimensions of identities: personal identities, professional identities, learner identities and community member identities (Figure 1). Personal identities cover community members' personal backgrounds, e.g. their age, gender, and degree programme. Professional identities entail members' perceived prior knowledge and experience in using online sharing applications, their motivation to participate in online communities and their commitment to participating in online sharing activities.

Learners' identities cover participants' beliefs in the benefits of online communities, and their sharing preferences. Sharing preferences are constituted by three subcategories, namely:

- The topics of discussions they preferred

- Their preferred means of participation, e.g. verbal rather than textual, giving rather than receiving or vice-versa

Their preferred medium of sharing, i.e. virtual or face-to-face discussions. Community member identities entail participants' perceived roles as members of online communities and their openness in relation to accepting comments from others, initiating new topics for discussion, and sharing their comments or thoughts, as well as teachers' preferences regarding who should become a member of their community and the extent to which teachers could give and take in their communities. 


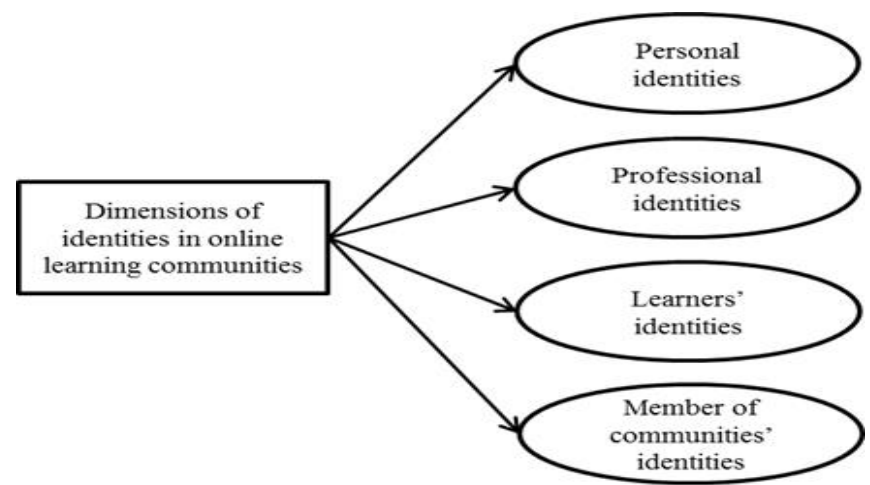

Fig. 1. Dimensions of Identities in Online Learning Communities (Khalid, 2013)

Computers in Education is a compulsory subject for first-year students in the Faculty of Education, Universiti Kebangsaan Malaysia. A website was created for this course which includes not only learning materials, assignments and announcements, but also an e-forum space for all students to share their thoughts and ideas (Figure 2). The purpose of the e-forum was to develop an online community that gathers all students from three programmes together in a single online environment. At the beginning of the semester, all students were briefed on the use of this e-forum, i.e., to gain ideas, share knowledge and seek support from other members. It was also stressed that in this online community, all members should learn from and with others. They were given the freedom to use whichever language they were more comfortable with, i.e. either English or Malay. They are also free to post any new topics based on their own needs. There are four lecturers for this course. The lecturers would consistently $\log$ into the e-forum to read students' discussions and give their feedback or advice where needed. This research is conducted to examine the dimensions of identities among the first year students in relation to their participation in online community. It is also aimed to identify the differences of identities based on gender and programs, and the see the correlation between the dimensions of identities.

\section{$2 \quad$ Methodology}

The overall number of students undertaking the Computers in Education course was 151 , from three programmes:

- Special Education

- Sports and Recreation

- Teaching English as a Second Language (TESL).

According to [31] sampling calculation, if a population is 150 , the desired sample would be 108. However, in order to ensure the return rate was not less than the suggested number, the questionnaire was administered to all students from these three programmes. The questionnaire was developed based on the previous research done 
via a qualitative approach. The emerging themes were used to create constructs, and the categories were used as a basis for item development. The questionnaire was developed using Google Forms and sent to the students via the e-forum on Weebly. The first section solicited respondents' background information, while the second section solicited their agreement with statements reflecting the dimensions of their professional, learner and communities member identities [30]. Participants were requested to indicate their agreement or disagreement with the statements based on a five-point Likert-type scale, from 'Totally Disagree' (1) to 'Totally Agree' (5). The questionnaire was pilot-tested to obtain feedback from a pilot test group from the target population. On the basis of their comments, the necessary revisions were made to the questionnaire before it was used for the actual study. The internal consistency estimate of reliability for the conditions statements using Cronbach's coefficient alpha for the pilot test ranged from .81 to .84 . As recommended by [31], these values surpassed the minimal consistency guidelines for an instrument to be judged acceptable.

In this study, an online questionnaire was disseminated to a total of 151 students who were taking the GE1155 course. Out of that total, 123 questionnaires were completed, making a final response rate of $81.45 \%$. The data collected were coded and summarised for data analysis. Data collected in the study were analysed using Statistical Package Social Science (SPSS) Version 23 for Windows. Descriptive statistics such as frequency distributions, percentages, means and standard deviations were used to describe participants' background information and their perceptions regarding their engagement in an e-forum. In order to determine possible relationships between the dimensions of identities tested in this study, a Pearson product-moment correlation analysis was employed. A two-tailed alpha level of .05 was used for the statistical testing. The strength of correlation was interpreted using [32] (Table 1).

Table 1. Coefficient of Correlation (Cohen, 1998)

\begin{tabular}{|c|l|}
\hline \multicolumn{1}{|c|}{$\mathbf{R}$} & \multicolumn{1}{c|}{ Interpretation } \\
\hline-+0.50 to -+1.0 large & Large (Strong) \\
\hline-+0.30 to -+0.49 & Medium (moderate) \\
\hline $\mathrm{r}=-+0.10$ to -+0.29 & small (weak) \\
\hline
\end{tabular}

\section{$3 \quad$ Finding and Discussions}

\subsection{Personal information}

As shown in Table 2, of these 123 students, 33 were from Teaching English as a Second Language (TESL), 48 were from Special Education, and 42 students were from Sports and Recreation. In terms of their gender, female students made up $65 \%$ of the overall participants $(n=80)$, while the rest were male students $(n=43)$. 
Table 2. Participants' Personal Information

\begin{tabular}{|l|c|c|}
\hline \multicolumn{1}{|c|}{ Gender } & N & Percentage \\
\hline Male & 42 & 34.1 \\
\hline Female & 80 & 65.0 \\
\hline Programme & N & Percentage \\
\hline TESL & 47 & 38.21 \\
\hline Sports \& Recreation & 42 & 34.14 \\
\hline Special Education & 33 & 26.82 \\
\hline
\end{tabular}

\subsection{Professional identities}

Professional identities in this study cover three main aspects: students' prior knowledge of online communities, their motivation to participate in online communities, and their commitment towards their online community. In terms of their prior knowledge related to participating in online communities, as indicated in Table 3, the majority of the students had participated in online learning groups $(\mathrm{M}=3.99$, S.D. $=0.88)$ and knew how to search for online forums $(M=3.92$, S.D. $=0.96)$. However, the students also pointed out that participating in the online forum required them to learn new skills $(\mathrm{M}=4.09$, S.D. $=0.86)$.

Motivation is vital in driving a person to take part in any community, as without motivation, they will not value participation and interaction in such a community. The analysis shows that the highest mean under this construct was for the item 'I joined the online forums/groups as I think I need extra support to improve myself' $(M=4.05$, S.D. $=0.88$ ). For the item 'I participated in the online forums/groups because the members in that group are easy to get along with', the mean score is 3.86 (S.D.= 0.99). The lecturers' recommendations also seemed to influence the students. This can be seen in the item 'I joined the online forums/groups because my lecturer asked us to do so' $(M=3.86$, S.D.=1.06). However, peers' influence showed the least agreement among the students, as shown in the item 'I joined the online forums/groups because my colleagues recommended it to me' $(M=3.55$, S.D.=1.16). These findings indicate that the students were driven by both inner and external motivations. Based on the means for each item, it appears likely that the students were more driven by their intrinsic motivation, i.e. to be able to get support from others in order to improve their skills. However, mutuality in engagement (Wenger et al., 2002) has also been found to be an important catalyst to spur interaction and engagement among members of an online community. It is undeniable that, in any online community, reciprocal engagement is crucial. Without this factor, members tend to disengage from the community. Although lecturers' influence was found to be among the factors motivating students, the influence from lecturers was not as strong as the students' own motivation to obtain something from the community. A similar result was shown for peers' influence, which had the lowest mean of all the factors. Indirectly, this finding shows the importance of how members see and value their online community with regard to their participation in that community.

Time can be a vital factor that influences the extent to which members would engage in their e-forum. The third sub-construct under professional identities is com- 
mitment. Four items in the questionnaire related to the time students spent to log onto their online forum and participate in the discussions. The findings seem to show that the majority of students would spend time to log onto their online community forum after class $(\mathrm{M}=3.59$, S.D. $=0.99)$ or during weekends $(\mathrm{M}=3.47$, S.D. $=0.99)$. It was intentionally planned that students use the e-forum outside the classroom period as in the tutorial sessions they needed to spend their time to complete tasks and do presentations in front of the class. The crucial time for them to complete their assignments was prior to the tutorial sessions.

Table 3. Participants' Professional Identities

\begin{tabular}{|c|l|c|c|}
\hline$\#$ & \multicolumn{1}{|c|}{ Prior knowledge } & Mean & S.D \\
\hline 1 & \multicolumn{1}{|c|}{ Motivation } & 4.01 & 0.88 \\
\hline 2 & I knowe participated in online learning groups to get new ideas & 3.93 & 0.96 \\
\hline 3 & Participating in online forums/groups required me to learn new skills & 4.12 & 0.86 \\
\hline$\#$ & \multicolumn{1}{|c|}{ Commitment } & Mean & S.D \\
\hline 1 & I joined the online forums/groups as I think I need extra support to improve myself & 4.05 & 0.88 \\
\hline 2 & $\begin{array}{l}\text { I participated in the online forums/groups because the members in that group are } \\
\text { easy to get along with }\end{array}$ & 3.86 & 0.99 \\
\hline 3 & I joined the online forums/groups because my colleagues recommended them to me & 3.55 & 1.16 \\
\hline 4 & I joined the online forums/groups because my lecturer asked us to do so & 3.86 & 1.06 \\
\hline$\#$ & & Mean & S.D \\
\hline 1 & I spent time during weekends to participate in the online forums/groups & 3.47 & 0.99 \\
\hline 2 & I spent time during class to participate in the online forums/groups & 3.24 & 1.21 \\
\hline 3 & I spent time after class to participate in the online forums/groups & 3.59 & 0.99 \\
\hline
\end{tabular}

\subsection{Learner Identities}

The third dimension is learner identities, which comprised two categories as shown in Table 4:

- Beliefs in the benefits of online communities

- Sharing preferences.

Based on the analysis, it was shown that students were positive in terms of their beliefs in the benefits of their online learning community. However, the most popular benefit of online communities was the fact that the interactions in online discussions with other members helped them to enhance their computer-related skills $(M=4.07$, S.D. $=0.87$ ). According to Wenger (1998), members of a community must have shared goals. These students showed that the motivation for them to engage in their online community was that it enhanced their skills in using computers for educational purposes. Another item that generated the same mean score was 'Participating in online forums/groups enabled me to enhance my computer-related skills' $(M=4.07$, S.D. $=0.87$ ). The overall findings show how students revealed their positive views on the benefits of their online community. Having a shared goal and needs within a community is crucial to guarantee that members will actively seek information and share ideas with others (Terehoff, 2002). 
In addition, students also viewed their online community as a platform for their professional development, as can be seen in this statement: 'Participation in online forums/groups is beneficial for my professional development' $(M=3.99$, S.D. $=0.82)$. This is in line with Lee (2007), who stresses the significance of a community-ofpractice approach for professional development, rather than a one-size-fits-all approach. This finding shows that an online community can be one suitable approach for the professional development of students in the Faculty of Education.

Among the objectives of the online community that was set up for this study was to provide students with opportunities to share their learning and past experiences. Although the mean score for the related statement ('I learn how to manage my assignments better through sharing experiences with others via online forums/groups') was 3.90 (S.D. $=0.94$ ), this is still considered as high. Students agreed that through collaborative sharing activities in their online community, they were able to complete their assignments successfully. The mean score for the statement 'Through participating in online forums/groups I could expand my networks' was 3.88 (S.D.=0.92). This finding indicates that for these students, expanding their network was not be their most important reason for joining their online community. This might be due to the fact that members of the GE1 155 online community were all students from the Faculty of Education who already knew one another in real life. Therefore, being in that online community did not give them an opportunity to know others whom they did not know before.

In relation to students' sharing preferences, the findings indicate the diversity of the students' learning preferences. However, the highest mean score was reported for the item 'I like to share any topics with others' $(M=3.64$, S.D.=1.01). Meanwhile, the item 'I prefer to share only topics related to my subject' showed a lower mean score $(\mathrm{M}=3.43$, S.D. $=1.04)$. From this finding, the fact that students prefer to discuss more general topics as opposed to specific topics via their online community was evident. In the GE1155 e-forum, students were given the freedom to initiate any topics that they felt were relevant, and the topics did not have to be related to the course (Computer in Education). In addition, some lecturers also created threads for discussing topics like mobile phones, food etc. The reason behind this was that in a community of practice, the bonding among members is important, and one measure to enhance relationships among members was through discussions about light topics (Wenger et al. 2002).

The item 'I prefer to have a verbal chat rather than typing up my ideas' $(M=3.59$, S.D. $=0.94)$ reflected an important finding for this study, although the mean score was not that high. This finding highlighted students' preferences regarding the way they communicated. It was indicated that students preferred to have a verbal chat rather than textual conversations. Perhaps they found that interactions in the tutorial classes gave them more satisfaction when they had the chance to have live conversations with their peers and lecturers, as compared to online discussions, which took time to get their questions answers or comments replied to. This could also be related to the fact that not many of the students frequently or consistently logged onto the e-forum. This could be related to the item 'I prefer face-to-face discussions over online platforms', for which the mean was 3.51 (S.D.=1.06), and where students also indicated their 
preference for having face-to-face discussions over online ones. Another discovery regarding students' learning preferences was the fact that most of them preferred to read others' comments or materials rather than writing down their own: for the item 'If I were in an online forum/group, I would prefer to read what others wrote rather than writing my comments', the mean score was 3.54 (S.D.=1.06). This finding is important to note as it describes students' learning preferences and suggests a strategy to be used to enhance students' level of engagement in online communities and how to ensure online discussions are satisfactory for students, as much as their face-to-face communications can offer.

Table 4. Participants' Learner Identities

\begin{tabular}{|c|l|c|c|}
\hline$\#$ & \multicolumn{1}{|c|}{ Belief in the benefits of online learning communities } & Mean & S.D \\
\hline 1 & $\begin{array}{l}\text { I learn how to manage my assignments better through sharing experiences with } \\
\text { others via online forums/groups }\end{array}$ & 3.90 & 0.94 \\
\hline 2 & $\begin{array}{l}\text { Participation in online forums/groups is beneficial for my professional develop- } \\
\text { ment }\end{array}$ & 3.99 & 0.82 \\
\hline 3 & Through participating in online forums/groups I can expand my networks & 3.88 & 0.92 \\
\hline 4 & $\begin{array}{l}\text { Participating in online forums/groups enabled me to enhance my computer- } \\
\text { related skills }\end{array}$ & 4.07 & 0.87 \\
\hline 5 & $\begin{array}{l}\text { Participating in online forums/groups will not be the same as face-to-face forums } \\
\text { in terms of their benefits } \quad 3.96\end{array}$ & 0.88 \\
\hline$\#$ & \multicolumn{1}{|c|}{ Sharing preferences } & Mean & S.D \\
\hline 1 & $\begin{array}{l}\text { If I were in an online forum/group, I would prefer to read what others wrote } \\
\text { rather than writing my own comments }\end{array}$ & 3.54 & 1.06 \\
\hline 2 & I prefer to have verbal chats rather than typing up my ideas & 3.59 & 0.94 \\
\hline 3 & I prefer face-to-face discussions over online platforms & 3.51 & 1.00 \\
\hline 4 & I like to share any topics with others & 3.64 & 1.01 \\
\hline 5 & I prefer to share only topics related to my subject & 3.43 & 1.04 \\
\hline 6 & I prefer to share stories of my experiences with others & 3.59 & 1.00 \\
\hline
\end{tabular}

\subsection{Community member identities}

The final dimension is community member identities, which is comprised of two sub-dimensions:

- Perceived role in the online community

- Openness.

The findings show in Table 5 that the mean score for the item 'I think I received more than I contributed in the online forums/groups' was 3.75 (S.D. $=0.76$ ), which is a bit higher than the mean score for the item 'I think I contributed more than I received in the online forums/groups' $(M=3.67$, S.D. $=0.86)$. This indicates that the students in this study perceived themselves as receiving more than they gave in their discussion process. This is supported by the item 'I prefer to give ideas/comments rather than asking questions' $(M=3.30$, S.D. $=0.98)$, which shows that students actually did not prefer to give comments or ideas within their online community. One of the successful characteristics of a community is that all members actively engage in interaction, and through this interaction, members are able to enhance their knowledge and skills 
[11]. Consequently, when members tend to hold back from being active participants, the interaction in an online community will not come alive.

In the online community in this study, it was anticipated that the students would be able to communicate their ideas and share their thoughts openly regardless of which programme they were from. There were also expected to be comments and responses given and taken among the members. The findings show that the students were open towards receiving any comments from other members of their online community. This can be seen in the item 'I am tolerant of any kinds of comments from others' $(\mathrm{M}=4.13$, S.D. $=0.78)$. The analysis also reveals that although students in this study had no hesitation in communicating with community members whom they did not know well ('I don't think I will have any hesitation to communicate with other members whom I do not know well': M=3.65, S.D. $=0.88$ ), they preferred to have people whom they knew as members of the forum ('I prefer to have people whom I know as members of the forum': $M=3.71$, S.D. $=1.00$ ). This is not a surprising finding, as [27] mention that for a community to be alive, members should know each other and their strengths. This issue is also associated with 'trust', as 'trust' can be a vital factor leading to community members' deep sharing of knowledge, and enabling them to avoid the 'gaps' that might prevent them from freely sharing what comes to their mind with their community. The students did not have much concern about the gender issue, as they showed a low mean for the item 'I think it is better to have members from the same gender as I am in the online forums/groups' ( $\mathrm{M}=2.87$, S.D.=1.25). The aspect of openness was also measured by the level of the students' willingness to initiate new topics for discussion and how they viewed their responses from others' perspectives. For the item 'I feel hesitant to initiate a new topic/to pose questions as doing so will reveal my weaknesses', students showed a slightly low agreement, which indicated that they were not hesitant to open or start new topics $(M=3.30$, S.D. $=1.05)$. The students were not worried about whether what they shared might not be valued by others ('I am afraid that what I share might not be something new for others': $M=3.33$, $\mathrm{S} . \mathrm{D}=1.09$ ) or that it would hurt others' feelings ('I am afraid that if I post any comments, it will hurt others' feelings': $M=3.35, S . D=1.17$ ). From these findings, it can be concluded that the students in this study were open towards sharing their thoughts and receiving ideas from others. This finding, however, does not match previous research which involved teachers in secondary schools [30], who found that many teachers were hesitant to share their thoughts due to anxieties about being belittled by other teachers, and some of them held back from 'giving too much', as doing so might be misinterpreted by others as being arrogant. In this study, however, the context was different as it involved university students, who saw themselves as people who were still looking for knowledge and who wanted to develop their skills. In contrast, in the previous research, the teachers had already established their profession and therefore had an issue in preserving their self-esteem. 
Table 5. Participants' Community Member Identities

\begin{tabular}{|c|l|c|c|}
\hline$\#$ & \multicolumn{1}{|c|}{ Perceived role in online community } & Mean & S.D \\
\hline 1 & I think I contributed more than I received in the online forums/groups & 3.67 & 0.86 \\
\hline 2 & I think I received more than I contributed in the online forums/groups & 3.75 & 0.76 \\
\hline 3 & I prefer to give ideas/comments rather than asking questions & 3.30 & 0.98 \\
\hline$\#$ & \multicolumn{1}{|c|}{ Openness } & Mean & S.D \\
\hline 1 & I prefer to have people whom I know as members of the forum & 3.71 & 1.00 \\
\hline 2 & $\begin{array}{l}\text { I don't think I will have any hesitation to communicate with other members whom I } \\
\text { do not know well }\end{array}$ & 3.64 & 0.89 \\
\hline 3 & $\begin{array}{l}\text { I feel hesitant to initiate a new topic/to pose questions as doing so will reveal my } \\
\text { weaknesses }\end{array}$ & 2.71 & 1.05 \\
\hline 4 & $\begin{array}{l}\text { I am not used to sharing everything I know as doing so will make others see me as } \\
\text { "showing off" }\end{array}$ & 2.52 & 1.09 \\
\hline 5 & I am afraid that what I share might not be something new for others & 2.68 & 1.09 \\
\hline 6 & I am afraid that if I post any comments, it will hurt others' feeling & 2.66 & 1.16 \\
\hline 7 & $\begin{array}{l}\text { I think it is better to have members from the same gender as I am in the online fo- } \\
\text { rums/groups }\end{array}$ & 2.87 & 1.25 \\
\hline 8 & I prefer to have students from other courses as members of my online forum/groups & 3.71 & 1.08 \\
\hline 9 & I am tolerant of any kinds of comments from others & 4.12 & 0.78 \\
\hline
\end{tabular}

\subsection{Relationships between the identity dimensions}

Another aim of this study is to examine the relationships between the dimensions of students' identities. Correlation analysis can measure the strength and direction of the linear relationship between two variables. In this study, the relationship between prior knowledge and motivation, commitment, belief in the benefit of online communities, perceived roles, sharing preferences, and openness was investigated using the Pearson product-moment correlation coefficient. Preliminary analyses were performed to ensure that there were no violations of the assumptions of normality, linearity and homoscedasticity.

As shown in Table 6, there was a strong positive correlation between prior knowledge and motivation $(r(123)=0.64, \quad, p<0.05)$, commitment $(r(123)=0.48$, , $p<0.05)$ and belief in the benefit of online communities $(r(123)=0.74,, p<0.05)$. This finding reveals that prior knowledge can be an important aspect that contributes to the way members of any online communities participate, as having a prior knowledge of how to operate a discussion platform and the way it works is associated with motivation. [33] also notes that for individuals to use any innovations, they should have knowledge of how the innovation works, and that knowledge and experience of using the innovation will lead to whether or not they will value the innovation. Prior knowledge will also lead to users' beliefs in the benefits of online communities. Again, this is in line with [33], who sets out that the 'triability' aspect of any innovation is vital in ensuring that the user sticks with the application of the innovation.

In addition, there is a medium positive correlation between prior knowledge and perceived roles $(r(123)=0.50, p<0.05)$. The majority of the students in this study stated that they had prior knowledge related to participating in online communities, and knew how to search for online forums (see Table 2), and these prior experiences influenced the way they carried out their roles as members of their online community. Another medium positive correlation can be seen between students' prior knowledge 
and sharing preferences $(r(123)=0.32,, p<0.05)$. Students may have developed their learning preferences based on their prior experiences taking part in other online discussion groups,. A weak positive correlation was shown between prior knowledge and openness $(r(123)=0.23,, p<0.05)$. This finding suggests the significance of prior knowledge and experience in ensuring students take part in online communities.

An important aspect that needs further investigation is the lack of correlation between students' openness and other elements of their identities. The only significant correlation that can be seen is between students' openness and their beliefs in the benefits of online communities (low positive correlation). Students' openness, which covers their willingness to accept comments from others, their concern about hurting others with their comments, and their fears of being seen as arrogant when showing their knowledge and abilities did not seem to correlate with their prior knowledge, motivation, commitment, perceived role and sharing preferences. These findings contrast with [30] results, which revealed that these traits were all associated with each other. However, [30] never provided a statistically significant analysis to show the relationship between these elements, as her research was solely based on qualitative data. Another possible explanation of these differences could be the participants themselves. [30] study involved secondary school teachers who were teaching English, science and mathematics from several technology-enhanced schools, while this research focused on university students. As [18] asserts, identities are related to how we look at ourselves and what others say about us. Adding to this, [34] also stresses the aspect of self-esteem, i.e. how one's self-esteem can have an impact upon the way they value their own selves, and thus lead to the way they value the things they do.

Table 6. The Correlations between the Professional, Learner and Community Member Dimensions of Identities

\begin{tabular}{|l|c|c|c|c|c|c|c|c|c|}
\hline \multicolumn{1}{|c|}{ Variable } & $\mathbf{1}$ & $\mathbf{2}$ & $\mathbf{3}$ & $\mathbf{4}$ & $\mathbf{5}$ & $\mathbf{6}$ & $\mathbf{7}$ & $\boldsymbol{M}$ & $\boldsymbol{S D}$ \\
\hline 1-Prior knowledge & -- & $.64^{* *}$ & $.50^{* *}$ & $.74^{* *}$ & $.53^{* *}$ & $.32^{* *}$ & $.22^{*}$ & 12.00 & 1.907 \\
\hline 2-Motivation & -- & -- & $.53^{* *}$ & $.59^{* *}$ & $.42^{* *}$ & $.35^{* *}$ & .18 & 15.32 & 2.836 \\
\hline 3-Commitment & -- & -- & -- & $.50^{* *}$ & $.28^{* *}$ & $.24^{* *}$ & -.023 & 13.68 & 2.743 \\
\hline $\begin{array}{l}\text { 4-Belief in the benefits of online } \\
\text { communities }\end{array}$ & -- & -- & -- & -- & $.54^{* *}$ & $.29^{* *}$ & $.26^{*}$ & 19.82 & 3.031 \\
\hline 5-Perceived roles & -- & -- & -- & -- & -- & $.53^{* *}$ & -.07 & 14.50 & 2.453 \\
\hline 6-Sharing preferences & -- & -- & -- & -- & -- & -- & -.15 & 21.22 & 3.097 \\
\hline 7-Openness & -- & -- & -- & -- & -- & -- & -- & 35.64 & 4.181 \\
\hline$* * p<.05$ & & & & & &
\end{tabular}

\section{Conclusion}

Identities in relation to participation in learning communities is a vital aspect to be understood if a successful online learning communities are to be achieved. The diversity of students' identities as shown in the findings of this study indicates the complexity of the aspect of identities. The way individuals see themselves, view learning and their preferences, as well as their beliefs in the benefits of online communities can be important factors leading to how they would behave and commit to their online 
sharing activities. This study is significant as it shows how understanding the aspects of identities could help stakeholder in designing successful online communities by putting the aspects of identities into consideration.

\section{$5 \quad$ References}

[1] Conrad, R. and Donaldson J. A. 2012. Continuing to engage the online learner activities and resources for creative instruction (1st ed.). San Francisco, CA: Jossey-Bass.

[2] Gao, F., Zhang, T., \& Frankin, T. 2013. Designing asynchronous online discussion environments: Recent progress and possible future directions, British Journal of Educational Technology, 44(3): 469-483. https://doi.org/10.1111/j.1467-8535.2012.01330.x

[3] Yang, Y., Yeh, H. \& Wong, W. 2010. The influence of social interaction on meaning construction in a virtual community, British Journal of Educational Technology, 41(2): 287306. https://doi.org/10.1111/j.1467-8535.2009.00934.x

[4] Boling, C. J., \& Martin, S. 2005. Supporting teacher change through online professional development. The Journal of Educators Online, 2 (1): 1-15. https://doi.org/10. 9743/JEO.2005.1.1

[5] Watson, S. 2006. Virtual mentoring in higher education: Teacher education and cyberconnections. International Journal of Teaching and Learning in Higher Education, 18 (3): 168-179.

[6] Collision, G., Elbaum, B., Haavind, S. \& Tinker, R. 2000. Facilitating online learning: Effective strategies for moderators. Madison, WI: Atwood Publishing.

[7] Bierema, L. L., \& Merriam, S. B. 2002. Virtual mentoring: Using technology to enhance the mentoring process. Innovative Higher Education, 26 (3): 211-227. https://doi.org/10.1 023/A:1017921023103

[8] Ensher, E., Heun, C., \& Blanchard, A. 2003. Online mentoring and computer mediated support: New directions in research. Journal of Vocational Behaviour, 63 (2): 264-288. https://doi.org/10.1016/S0001-8791(03)00044-7

[9] Day, C. 1999. Developing teachers: The challenges of lifelong learning. UK: Falmer Press.

[10] Wenger, E., McDermont, R., \& Snyder, W. M. 2002. Cultivating communities of practice. Boston: Harvard University Business School Press.

[11] Young, M. L., \& Tseng, F. C. 2008. Interplay between physical and virtual settings for online interpersonal trust formation in knowledge sharing practice. Cyber-Psychology and Behaviour, 11 (1): 55-64. https://doi.org/10.1089/cpb.2007.0019

[12] Glass, N., \& Walter, R. 2000. An experience of peer mentoring with student nurses: enhancement of personal and professional growth. Journal of Nursing Education, 39 (4): 1-6.

[13] MY Daud, F Khalid, M Ahmad, MJA Rahman, AA Karim. 2016. “To Participate or Not?”: Identifying the Factors Affecting University Students' Participation in an eForum. Creative Education 7 (18), 2791 https://doi.org/10.4236/ce.2016.718259

[14] Terehoff, I. 2002. Elements of adult learning in teacher professional development. NASSP Bulletin, 86: 65-77. https://doi.org/10.1177/019263650208663207

[15] Day, C. 2000. Professional development and teacher professionalism: Choice and consequence in the twenty first century. Paper presented at the Continuing Teacher Education and School Development Symposium, Aristotle University, Thessaloniki, Greece.

[16] Doukas, S. 2004. Teachers' continuing professional development: The case of a Greek private Further Education College (Unpublished master's dissertation). University of Nottingham, Nottingham, UK. 
[17] Lieberman, A. 1995. Practices that support teacher development. Phi Delta Kappan, 76 (8): 591-596.

[18] Day, C. 2004. A passion for teaching. London: Routledge Falmer. https://doi.org/10.4 324/9780203464342

[19] Hofstede, G. 2001. Culture's consequences: comparing values, behaviours, institutions and organisations across nations ( 2 nd ed.). Thousand Oaks, CA: Sage.

[20] Khalid, F. 2014. The impact of teaching practice experience in shaping pre-service teachers' professional identities. Mediterranean Journal of Social Science, 5 (20), 1921-1927. https://doi.org/10.5901/mjss.2014.v5n20p1921

[21] Ajzen, I., \& Fishbein, M. 1980. Understanding attitudes and predicting social behavior. Englewood Cliffs, NJ: Prentice-Hall.

[22] Greener, S. 2009. Talking online: Reflecting on online communication tools. CampusWide Information System, 26 (3): 178-190. https://doi.org/10.1108/10650740910967366

[23] Fishbein, M., \& Azjen, I. 1975. Belief, attitude, intention and behaviour: An introduction to theory and research. Reading MA: Addison-Wesley.

[24] Bandura, A. 1986. Social foundations of thoughts and action: A social cognitive theory. Englewood Cliffs, NJ: Prentice-Hall.

[25] Chene, A., \& Siguouin, R. 1997. Reciprocity and older learners. Educational Gerontology (23): 253-272. https://doi.org/10.1080/0360127970230305

[26] Day, C., Sammons, P., Stobart, G., Kington, A., \& Gu, Q. 2007. Teachers Matter. New York: Open University Press.

[27] Wenger, E. 1998. Communities of practice: Learning, meaning, and identity. NY: Cambridge University Press. https://doi.org/10.1017/CBO9780511803932

[28] Deschamps, J. C. \& Devos, T. 1998. Regarding the relationship between social identity and personal identity. In Worchel, S., Francisco M. J., Pa'ez, D., \& Deschamps, J. C. (Eds.). Social Identity: International perspectives (pp. 1-12). London: SAGE Publications. https://doi.org/10.4135/9781446279205.n1

[29] Beijaard, D., Beijaard, N., Verloop, T., \& Vermunt, J.D. 1995. Teachers' perceptions of professional identity: an exploratory study from a personal knowledge perspective. Teaching and Teacher Education, 16: 749-64. https://doi.org/10.1016/S0742-051X(00)00023-8

[30] Khalid, F. 2018. Understanding the dimensions of identities and its impact upon member's participation in an online community of practice. Journal of Information Technology Education: Research, 17, 527-547.

[31] Field, A. P. and Miles, J. 2012. Discovering statistics using R. London: Sage.

[32] Cohen, J. (1988). Statistical power analysis for the behavioral sciences (2nd ed.). Hillsdale, NJ: Lawrence Earlbaum Associates.

[33] Rogers, E.M. 2003. Diffusion of innovations (5th ed.). New York: Free Press.

[34] Kelchtermans, G. 1996. Teacher vulnerability: Understanding its moral and political roots. Cambrdige Journal of Education, 26 (3): 307-324. https://doi.org/10.10 $\underline{80 / 0305764960260302}$

\section{Author}

Fariza Khalid is a senior lecturer at the Faculty of Education, Universiti Kebangsaan Malaysia. Her research interests are teacher identities, online communities of practice, augmented reality and emerging technologies for educational purposes. At present, she leads a research project on Cyber Security awareness among youngsters. Fariza has a Ph.D. in Instructional Technology from the University of Nottingham, 
M.Sc. in Educational Technology from Universiti Putra Malaysia, and B.A. in Islamic Education from University of Malaya. She actively participates in research exhibitions at international as well as national level. To date, she had won more than 30 awards. Among her achievements are 'The Best Edublog/Wiki' in conjuncture with the Malaysian National University Carnival on e-Learning in 2015, 2nd place of Reimagining \& Redesigning Malaysian Higher Education Award under the category of 'Virtual Immersive Learning Experience' in 2017 and recently, in 2018, she received 'The Best Educator Award" from the university.

Article submitted 2018-01-04. Resubmitted 2018-07-10. Final acceptance 2018-09-16. Final version published as submitted by the authors. 